\title{
Prevalence and genotypic analysis of plasmid- mediated $\beta$-lactamases among urinary Klebsiella pneumoniae isolates in Moroccan community
}

\author{
Abouddihaj Barguigua ${ }^{1,2}$, Fatima El Otmani ${ }^{2}$, Mustapha Talmi ${ }^{2}$, Ahmed Reguig ${ }^{1}$, Loubna Jamali ${ }^{1}$, \\ Khalid Zerouali ${ }^{3}$ and Mohammed Timinouni ${ }^{1}$
}

The aim of this study is to assess the prevalence and molecular characterization of the extended spectrum $\beta$-lactamases (ESBL)-producing Klebsiella pneumoniae isolated from community acquired urinary tract infections and collected in five Moroccan cities during a 2010 survey. In all, $34(7.5 \%)$ of the $453 \mathrm{~K}$. pneumoniae isolates studied were positive for an ESBL phenotype and $91.1 \%$ of these isolates were multidrug resistant. The bla

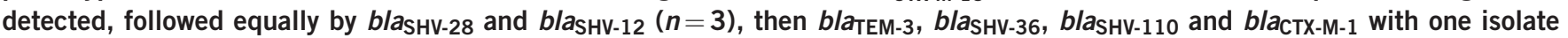
for each $(n=1)$. Eight isolates co-expressed more than one ESBL with bla bla $a_{\mathrm{SHV}-11}, b / a_{\mathrm{SHV}-32}, b / a_{\mathrm{SHV}-26}, b / a_{\mathrm{SHV}-76}, b / a_{\mathrm{TEM}-1}, b / a_{\mathrm{TEM}-1 \mathrm{~b}}$ and $b a_{\mathrm{OXA}-1}$. Plasmid-mediated AmpC $\beta$-lactamase genes, bla ${ }_{\mathrm{ACT}-2}$, bla $a_{\text {DHA-1 }}$ and a new $\beta$-lacatamase named $b / a_{\mathrm{EBC}-1464}$, were detected in $11.7 \%$ of isolates. Fourteen $(41.1 \%)$ isolates harbored qnr genes; qnrA6 $(n=1), q n r B 1(n=8), q n r B 2(n=1)$ and $q n r S 1(n=4)$ types were detected. Twenty-six isolates $(76.4 \%)$ were positive for $\operatorname{aac}\left(6^{\prime}\right)-l b-c r$ gene. Results of conjugation experiments indicated that $b / a_{\mathrm{CTX}-\mathrm{M}-15}, \mathrm{bla}_{\mathrm{TEM}-1 \mathrm{~b}}, b_{\mathrm{O}} \mathrm{OXA-1}, \operatorname{aac}\left(6^{\prime}\right)$ $I b-c r$ and $q n r B 1$ genes were co-transferred and that these genes were carried by a conjugative plasmid of high molecular weight. With the exception of $q n r B 1$, all the antibiotic resistance genes were clustered in a 12-kb region. The results of this work report the genetic diversity of ESBL genes, with the CTX-M-15 enzyme being most common among ESBL-producing K. pneumoniae in Moroccan community. Furthermore, a major finding is that bla $\mathrm{EBC}_{\mathrm{EB}-1464}$ detection is a first in Morocco. The Journal of Antibiotics (2013) 66, 11-16; doi:10.1038/ja.2012.91; published online 24 October 2012

Keywords: $\beta$-lactamases; community-acquired infection; K. pneumoniae; Morocco; plasmid mediated quinolone resistance

\section{INTRODUCTION}

Urinary tract infections (UTIs) remain the common infections diagnosed in outpatients, as well as in hospitalized patients. ${ }^{1}$ Escherichia coli and Klebsiella pneumoniae have been reported as the most common organisms causing UTIs. ${ }^{2}$ Furthermore, $K$. pneumoniae is an important pathogen both in the community and the hospital setting to cause severe infections. ${ }^{3}$ During the last decade, extended spectrum $\beta$-lactamases (ESBLs) type have emerged in the community setting among $K$. pneumoniae isolates, on plasmids that frequently bear additional resistance determinants. The class A ESBLs, TEM, SHV and CTX-M types, are the most widespread and clinically relevant. TEM and SHV types are derived from penicillinases TEM-1, TEM-2 and SHV-1 and are characterized by several single amino-acid substitutions. These mutations allow them to hydrolyze extended spectrum cephalosporins. More than 200 TEM enzymes and more than 160 different mutants of SHV have been reported (www.lahey.org/Studies/). The plasmid-encoded CTX-M family members, which confer high levels of resistance to extended spectrum cephalosporins, have emerged in several continents around the world. More than 130 different variants of CTX-M enzymes are currently known (www.lahey.org/Studies/). The genes encoding these $\beta$-lactamases are often located on large plasmids that also encode genes for resistance to other antibiotics. ${ }^{4}$ Furthermore, there is an increasing tendency for pathogens to produce multiple $\beta$ lactamases. ${ }^{5}$

ESBL producing Enterobacteriaceae strains, predominated by E. coli and $K$. pneumoniae, have been isolated from different hospitals in Morocco. ${ }^{6,7}$ The $\beta$-lactamase genes detected in Moroccan hospitals isolates were $b l a_{\mathrm{TEM}}, b l a_{\mathrm{SHV}}, b l a_{\mathrm{DHA}}$ and $b l a_{\mathrm{OXA}}$ types. ${ }^{6,8}$ Recently, $b l a_{\text {OXA-48 }}$ carbapenemase gene has been detected in one K. pneumoniae isolate in Rabat city. ${ }^{4}$ Here, we report the prevalence of ESBL producing K. pneumoniae isolated from UTIs in Moroccan community and the characterization of their $\beta$-lactamases enzymes. Current knowledge on antimicrobial susceptibility pattern of this uropathogen is mandatory for appropriate therapy, so the accumulation of other resistance genes by isolates was also investigated.

${ }^{1}$ Molecular Bacteriology Laboratory, Pasteur Institute of Morocco, Casablanca, Morocco; ${ }^{2}$ Department of Biology, Microbiology, Health and Environment Team, School of Sciences, Chouaib Doukkali University, EL Jadida, Morocco and ${ }^{3}$ University Hospital Center Ibn Rochd, Casablanca, Morocco 


\section{MATERIALS AND METHODS}

\section{Bacterial isolates}

A total of 453 non-duplicate community acquired uropathogenic K. pneumoniae isolated from urine specimens (corresponding to an overall incidence in UTIs of 17\%) were examined in this study. They were collected from January to December 2010 from medical analysis laboratories of five Moroccan cities: Casablanca situated in the center of Atlantic Coast of Morocco; El Jadida located $100 \mathrm{~km}$ south west of Casablanca; Settat situated $72 \mathrm{~km}$ South of Casablanca; Rabat located $95 \mathrm{~km}$ north east of Casablanca and Meknes located $230 \mathrm{~km}$ north east of Casablanca.

The K. pneumoniae isolated from hospitalized or previous hospitalized patients during the study year were excluded. Strains were named (Kpp (K. pneumoniae)) and numbered independently from isolation date.

\section{Antimicrobial drug susceptibility testing}

Antimicrobial drug susceptibility was determined by the disk-diffusion method on Mueller-Hinton (MH) agar plates (Bio-Rad, Marnes-la-Coquette, France) as recommended by the French Society for Microbiology (FSM; 2009) (http:// www.sfm-microbiologie.org). The following antimicrobial agents (Bio-Rad) were tested: amoxicillin $(10 \mu \mathrm{g})$, amoxicillin/clavulanic acid $(20 / 10 \mu \mathrm{g})$, cefoxitin $(30 \mu \mathrm{g})$, cefotaxime $(30 \mu \mathrm{g})$, ceftazidime $(30 \mu \mathrm{g})$, cefepime $(30 \mu \mathrm{g})$, imipenem $(10 \mu \mathrm{g})$, aztreonam $(30 \mu \mathrm{g})$, nalidixic acid $(30 \mu \mathrm{g})$, ciprofloxacin $(5 \mu \mathrm{g})$, gentamicin $(10 \mu \mathrm{g})$, tobramycin $(10 \mu \mathrm{g})$, kanamycin $(30 \mu \mathrm{g})$, amikacin $(30 \mu \mathrm{g})$, trimethoprim/sulfamethoxazole $(1.25 / 23.75 \mu \mathrm{g})$, trimethoprim $(5 \mu \mathrm{g})$ and tetracycline $(30 \mu \mathrm{g})$. Multidrug resistance (MDR) was defined as those resistant to at least two of the antibiotic classes in addition to the $\beta$-lactams. E. coli ATCC 25922 was used as quality control strain.

ESBL production was detected by the double-disc synergy test (DDST) using clavulanic acid-amoxicillin $(20 / 10 \mu \mathrm{g})$ and ceftazidime $(30 \mu \mathrm{g})$, cefotaxime $(30 \mu \mathrm{g})$, aztreonam $(30 \mu \mathrm{g})$ and cefepime $(30 \mu \mathrm{g})$ on $\mathrm{MH}$ agar as recommended by the FSM (2009) (http://www.sfm-microbiologie.org). Isolates showing a DDST-negative and resistant to third generation cephalosporins were screened for ESBL phenotype; ESBL + AmpC screening identification kit (Rosco Diagnostica, Taastrup, Denmark) that included antibiotic impregnated tablets: cefotaxime $30 \mu \mathrm{g}$, cefotaxime $30 \mu \mathrm{g}+$ clavulanate, cefotaxime $30 \mu \mathrm{g}+$ cloxacillin, cefotaxime $30 \mu \mathrm{g}+$ cloxacillin + clavulanate were used. By measuring differences in zone of inhibition, they were categorized into strains that produced ESBL or AmpC or both according to the manufacturer's instructions.

\section{Preparation of DNA template for PCR}

DNA templates for PCR process were generated by suspending five colonies of an overnight culture of $K$. pneumoniae isolates growing on Luria Bertani agar (Bio-Rad) in $500 \mu \mathrm{l}$ of DNase- and RNase-free water (Invitrogen, Paisley, UK). The suspension was boiled at $100^{\circ} \mathrm{C}$ for $10 \mathrm{~min}$ in thermal block (Polystat 5; Bioblock Scientific, France), and then centrifuged at $19000 \mathrm{~g}$ for $5 \mathrm{~min}$. An aliquot of $1 \mu \mathrm{l}$ of the supernatant was used as DNA template for PCR.

\section{Identification of phylogenetic groups}

The identification of phylogenetic group affiliation of strains was conducted by gyrA PCR-restriction fragment length polymorphism using restriction enzymes TaqI and HaeIII as previously described. ${ }^{3}$

\section{Detection of $\beta$-lactamase-encoding genes}

$K$. pneumoniae isolates were screened by PCR for the following $\beta$-lactamaseencoding genes: $b l a_{\mathrm{CTX}-\mathrm{M}}$ phylogenetic lineage groups 1,2 and $9, b a_{\mathrm{TEM}}$, $b l a_{\mathrm{SHV}}, b l a_{\mathrm{OXA}-1}, b l a_{\mathrm{PER}}, b l a_{\mathrm{VEB}}$ and $b l a_{\mathrm{AmpC}}$ as described previously. ${ }^{9,10}$

\section{Detection of plasmid-mediated quinolone resistance genes}

All ESBL-producing strains were screened by PCR for $q n r$ genes ( $q n r A$, $q n r B$ and $q \eta r S)$ and $a a c\left(6^{\prime}\right)-I b-c r$ gene as described previously. ${ }^{9}$

All primers used in this work are shown in Table 1.

\section{Sequencing of resistance genes}

The primers used for resistance gene amplification targeting a region allow the sequencing of the whole coding sequence. Both strands of the purified amplicons were sequenced with a Genetic Analyzer $3130 \times 1$ sequencer (Applied Biosystems, Foster City, CA, USA) with the same primers used for PCR amplification. The nucleotide and deduced protein sequences were analyzed with software available over the Internet at the National Center for Biotechnology Information website (see www.ncbi.nlm.nih.gov)

\section{Conjugation experiments and plasmid analysis}

Conjugation assays were performed by a broth mating and filter mating methods using azide-resistant $\left(\mathrm{Az}^{\mathrm{R}}\right)$ mutant of E. coli $\mathrm{K}_{12} \mathrm{~J}_{5}$ as recipient strain. Transconjugants were selected on the MH agar containing azide $\left(200 \mathrm{mgl}^{-1}\right)$ and cefotaxime $\left(2 \mathrm{mgl}^{-1}\right)$ (Bio-Rad) and incubated for $18-24 \mathrm{~h}$ at $37^{\circ} \mathrm{C}$. When not successful at the first attempt, mating experiments were repeated up to three times.

The putative transconjugants were tested for susceptibility to all antibiotics, as indicated previously, to identify transferable antibiotic resistance determinants. Minimal inhibitory concentrations of $\beta$-lactams (amoxicillin, cefotaxime, ceftazidime, cefoxitin and cefepime), quinolones (nalidixic acid, ciprofloxacin), aminoglycosides (gentamicin, kanamycin, amikacin and streptomycin) and tetracycline were determined by agar dilution method according to guidelines of the FSM (2009) (http://www.sfm-microbiologie.org) for ESBLcarrying strains and their transconjugants.

Plasmid DNA extraction from both donor and transconjugants was performed using a Plasmid Midi Prep Kit (Qiagen Ltd, West Sussex, UK) according to manufacturer's instructions. The sizes of plasmids were estimated by electrophoresis on $0.7 \%$ agarose using the plasmids from E.coli V517 as the standard markers. ${ }^{11}$

\section{Genetic environment of $b l a_{\mathrm{CTX}-\mathrm{M}}$}

The genetic organization of $b l a_{\mathrm{CTX}-\mathrm{M}}$ genes and the sequencing of the regions surrounding these genes were investigated by PCR. The internal IS26 and ISEcp1 forward primers and the CTX-M reverse consensus primer (MA1 reverse) were used to investigate the promoter regions of the $b l a_{\mathrm{CTX}-\mathrm{M}}$ genes. ${ }^{12}$ Primer orf477-IRR matches the alternative ISEcp1 IRR. ${ }^{13}$

The plasmid DNA obtained from the transconjugants ( $K$. pneumoniae Kpp.319 and Kpp.20) was used to investigate the flanking regions of the

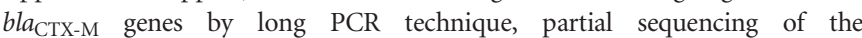
regions surrounding these genes (Table 1) and PCR analysis as described previously. ${ }^{12-14}$

\section{RESULTS}

\section{Prevalence of extended spectrum $\beta$-lactamases producing $K$. pneumoniae isolates}

Among the 453 community $K$. pneumoniae strains responsible for UTIs studied, 34 were ESBL producers, so the overall prevalence was $7.5 \%$ (3.7-9.0\% depending on the cities) (Table 2).

\section{Antimicrobial drug susceptibility}

Disk-diffusion susceptibility testing indicated high prevalence of resistance to various antimicrobial agents: $91.1 \%$ of these isolates were MDR. All strains were resistant to amoxicillin, amoxicillin/ clavulanic acid, cefotaxime, ceftazidime, cefepime and aztreonam. Eight $(23.5 \%)$ strains were resistant to cefoxitin. Five (14.7\%) strains show intermediate level of resistance to imipenem. We observed a substantial level of resistance to quinolones; 28 strains (77.7\%) had an intermediate level of resistance or were fully resistant to nalidixic acid, and ciprofloxacin. Of the 34 ESBL-carrying strains, only one was susceptible to nalidixic acid and had intermediate resistance level to ciprofloxacin. Cotrimoxazole and tetracycline resistance was observed in $27(79.4 \%)$ and $31(91.1 \%)$ strains, respectively. Twentynine strains $(85.3 \%)$ were resistant to at least one of the four 
Table 1 Primers sets used for PCR amplification and sequencing

\begin{tabular}{|c|c|c|c|}
\hline Gene or location & Primer ${ }^{\mathrm{a}}$ & Primer sequence $\left(5^{\prime} \rightarrow 3^{\prime}\right)$ & Reference \\
\hline \multirow[t]{2}{*}{ blacTX-M group 1} & CTX-M1( +) & GGTTAAAAAATCACTGCGTC & Barguigua et al. ${ }^{9}$ \\
\hline & CTX-M1(-) & TTGGTGACGATTTTAGCCGC & \\
\hline \multirow{2}{*}{ bla CTX-M group2 } & CTX-M2( +) & ATGATGACTCAGAGCATTCG & Barguigua et al. ${ }^{9}$ \\
\hline & CTX-M2(-) & TGGGTTACGATTTTCGCCGC & \\
\hline \multirow[t]{2}{*}{ blacTX-M group9 } & CTX-M9( +) & ATGGTGACAAAGAGAGTGCA & Barguigua et al. ${ }^{9}$ \\
\hline & CTX-M9(-) & CCCTTCGGCGATGATTCTC & \\
\hline \multirow[t]{2}{*}{ blatem } & $a-216$ & ATAAAATTCTTGAAGACGAAA & Barguigua et al. ${ }^{9}$ \\
\hline & $a-217$ & GACAGTTACCAATGCTTAATCA & \\
\hline \multirow[t]{2}{*}{ blasHV } & Os-5 & CGCCGGGTTATTCTTATTTGTCGC & Barguigua et al. ${ }^{9}$ \\
\hline & Os-6 & CGCCGGGTTATTCTTATTTGTCGC & \\
\hline \multirow[t]{2}{*}{ bla $0 \times A$} & Oxa-1 & CCAAAGACGTGG & Barguigua et al. ${ }^{9}$ \\
\hline & Oxa-2 & GTTAAATTCGACCCCAAGTT & \\
\hline \multirow[t]{2}{*}{ blaper } & $\operatorname{per}(+)$ & CCTGACGATCTGGAACCTTT & Barguigua et al. ${ }^{9}$ \\
\hline & $\operatorname{per}(-)$ & GCAACCTGCGCAAT(GA)ATAGC & \\
\hline \multirow[t]{2}{*}{ blaveB } & $\operatorname{veb}(+)$ & ATTTCCCGATGCAAAGCGT & Barguigua et al. ${ }^{9}$ \\
\hline & $\operatorname{veb}(-)$ & TTATTCCGGAAGTCCCTGT & \\
\hline \multirow[t]{2}{*}{$q n r A$} & $\operatorname{qnr} A(+)$ & TTCTCACGCCAGGATTTGAG & Barguigua et al. ${ }^{9}$ \\
\hline & qnrA( -$)$ & TGCCAGGCACAGATCTTGAC & \\
\hline \multirow[t]{2}{*}{$q n r B$} & $\mathrm{qnrB}(+)$ & TGGCGAAAAAAATT(GA)ACAGAA & Barguigua et al. ${ }^{9}$ \\
\hline & qnrB( $(-)$ & GAGCAACGA(TC)GCCTGGTAG & \\
\hline \multirow[t]{2}{*}{ qnrs } & qnrs $(+)$ & GACGTGCTAACTTGCGTGAT & Barguigua et al. ${ }^{9}$ \\
\hline & qnrS (-) & AACACCTCGACTTAAGTCTGA & \\
\hline \multirow[t]{2}{*}{$\operatorname{aac}\left(6^{\prime}\right)-1 b$} & $\operatorname{aac}\left(6^{\prime}\right)-\operatorname{lb}(+)$ & ATGACTGAGCATGACCTTG & Barguigua et al. ${ }^{9}$ \\
\hline & $\operatorname{aac}\left(6^{\prime}\right)-\operatorname{lb}(-)$ & AACCATGTACACGGCTGG & \\
\hline \multirow[t]{2}{*}{ blafox } & foxM(+) & AACATGGGGTATCAGGGAGATG & Pérez-Pérez and Hanson ${ }^{10}$ \\
\hline & foxM( -$)$ & CAAAGCGCGTAACCGGATTGG & \\
\hline \multirow[t]{2}{*}{$b / a_{A C C}$} & $\operatorname{accM}(+)$ & AACAGCCTCAGCAGCCGGTTA & Pérez-Pérez and Hanson ${ }^{10}$ \\
\hline & $\operatorname{accM}(-)$ & TTCGCCGCAATCATCCCTAGC & \\
\hline \multirow[t]{2}{*}{ bla } & $\operatorname{ebcM}(+)$ & TCGGTAAAGCCGATGTTGCGG & Pérez-Pérez and Hanson ${ }^{10}$ \\
\hline & ebcM(-) & CTTCCACTGCGGCTGCCAGTT & \\
\hline \multirow[t]{2}{*}{ blamox } & $\operatorname{moxM}(+)$ & GCTGCTCAAGGAGCACAGGAT & Pérez-Pérez and Hanson ${ }^{10}$ \\
\hline & $\operatorname{moxM}(-)$ & CACATTGACATAGGTGTGGTGC & \\
\hline \multirow[t]{2}{*}{ bla } & $\operatorname{citM}(+)$ & TGGCCAGAACTGACAGGCAAA & Pérez-Pérez and Hanson ${ }^{10}$ \\
\hline & $\operatorname{citM}(-)$ & TTTCTCCTGAACGTGGCTGGC & \\
\hline \multirow[t]{2}{*}{ bla } & dhaM $(+)$ & AACTTTCACAGGTGTGCTGGGT & Pérez-Pérez and Hanson ${ }^{10}$ \\
\hline & dhaM $(-)$ & CCGTACGCATACTGGCTTTGC & \\
\hline \multirow[t]{2}{*}{ IS26-blactX-M } & IS26 & GTTTATCACCACCGAC & Eckert et al. ${ }^{12}$ \\
\hline & CTX-MA3 (-) & ACYTTACTGGTRCTGCACAT & \\
\hline \multirow{2}{*}{ ISEcp1-bla } & $\mid S E c p 1$ & AAAAATGATTGAAAGGTGGT & Eckert et al. ${ }^{12}$ \\
\hline & СTX-MA3 (-) & ACYTTACTGGTRCTGCACAT & \\
\hline \multirow[t]{2}{*}{ blaTEM-ISEcp1 } & ISEcp (-) & TTCAATAAAATCAAAAATCCCA & Lavollay et al. ${ }^{14}$ \\
\hline & Tem $1(+)$ & ATACCGCACCACATAGCAGA & \\
\hline \multirow[t]{2}{*}{ blactX-м - Orf477 } & $\mathrm{P} 1 \mathrm{~A}(+)$ & GGCGATCCGCGTGATACCAC & Literacka et al. ${ }^{13}$ \\
\hline & orf477 (-) & CCTGGGACCTACGTG & \\
\hline
\end{tabular}

$a_{+}$, Primer forward; -, Primer reverse.

Table 2 Distribution and prevalence of ESBL-producing K. pneumoniae isolates in Moroccan cities

\begin{tabular}{lccc}
\hline & \multicolumn{3}{c}{ ESBL-producing } \\
City & Total K. pneumoniae & K. pneumoniae & Frequency (\%) \\
\hline Rabat & 136 & 10 & 7.3 \\
Casablanca & 161 & 14 & 8.7 \\
El Jadida & 107 & 7 & 6.5 \\
Meknès & 22 & 2 & 9.0 \\
Settat & 27 & 1 & 3.7 \\
Total & 453 & 34 & 7.5 \\
\hline
\end{tabular}

aminoglycosides tested. The most frequently observed phenotype profile included resistance to gentamicin, tobramycin and kanamycin ( $n=23 ; 79.3 \%$ of the strains) followed by resistance to gentamicin and tobramycin ( $n=4 ; 13.7 \%$ of the strains) (Table 3$)$.

Phylogenetic types of extended spectrum $\beta$-lactamase producing K. pneumoniae

In total, $29(82.3 \%)$ isolates were identified as $K$. pneumoniae phylogenetic group I (KpI), $4(11.7 \%)$ as K. pneumoniae phylogenetic group II (KpII) and $2(5.8 \%)$ as K. pneumoniae phylogenetic group III (KpIII). 
Table 3 Characteristics of the ESBL-producing K. pneumoniae isolates collected in Moroccan community

\begin{tabular}{|c|c|c|c|c|c|c|c|}
\hline & & & Phylogenetic & & & $\mathrm{aac}\left(6^{\prime}\right)-\mathrm{lb}$ & \\
\hline Крp.334 & 04 March 2010 & Meknes & $\mathrm{Kpl}$ & CTX-M-1; TEM-1; SHV-11; OXA-1 & qnrS1 & $+(\mathrm{cr})$ & NA; CIP; GM; K; TM; TET; SXT \\
\hline Kpp.390 & 04 October 2010 & Rabat & $\mathrm{Kpl}$ & CTX-M-15; SHV-1 & - & - & - \\
\hline Kpp.329 & 24 April 2010 & EL Jadida & $\mathrm{Kpl}$ & CTX-M-15; SHV-1; OXA-1 & - & $+(\mathrm{cr})$ & NA; CIP; GM; K; TM; TET; SXT; TMP \\
\hline Kpp.373 & 22 September 2010 & Rabat & $\mathrm{Kpl}$ & CTX-M-15; SHV-36; OXA-1 & - & $+(\mathrm{cr})$ & $\mathrm{NA}^{\mathrm{b}} ; \mathrm{CIP}^{\mathrm{b}} ; \mathrm{GM} ; \mathrm{K} ; \mathrm{TM} ; \mathrm{TET}$ \\
\hline Kpp.392 & 11 November 2010 & Rabat & $\mathrm{Kpl}$ & CTX-M-15; TEM-1; SHV-12 & qnrS1 & - & GM; TMP \\
\hline Kpp.370 & 05 October 2010 & Rabat & $\mathrm{Kpl}$ & CTX-M-15; TEM-1; SHV-26 & - & $+(\mathrm{cr})$ & CIPb; GM; K; TM; TET' ; SXT; TMP \\
\hline Кpp.377 & 15 September 2010 & Rabat & $\mathrm{Kpl}$ & СTX-M-15; TEM-1; SHV-26; OXA-1 & - & $+(\mathrm{cr})$ & GM; K; TM; TET; SXT; TMP \\
\hline Kpp.394 & 12 November 2010 & Casablanca & $\mathrm{Kpl}$ & CTX-M-15; TEM-1; SHV-28; OXA-1 & - & $+(\mathrm{cr})$ & NA; CIP; K; TM; TET; SXT; TMP; IMPb \\
\hline Kpp.328 & 16 June 2010 & Casablanca & $\mathrm{Kpl}$ & CTX-M-15; TEM-1; SHV-32 & - & - & $\mathrm{TET}^{\mathrm{b}} ; \mathrm{SXT} ; \mathrm{TMP}$ \\
\hline Крp.374 & 20 September 2010 & Rabat & $\mathrm{Kpl}$ & CTX-M-15; TEM-1; SHV-76; OXA-1 & qnrB2 & $+(\mathrm{cr})$ & NA; CIP; GM; K; TM; TET; SXT; TMP \\
\hline Kpp.313 & 01 April 2010 & Casablanca & $\mathrm{Kpl}$ & CTX-M-15; TEM-1b; SHV-1; OXA-1 & $q n r B 1$ & $+(\mathrm{cr})$ & NA; CIP; GM; K; TM; AN; TET; TMP; IMP' \\
\hline Kpp.319 & 13 May 2010 & Casablanca & $\mathrm{Kpl}$ & CTX-M-15; TEM-1b; SHV-1; OXA-1 & qnrB1 & $+(\mathrm{cr})$ & NA; CIP; GM; K; TM; TET; SXT; TMP \\
\hline Крp.317 & 10 May 2010 & Casablanca & $\mathrm{Kpl}$ & CTX-M-15; TEM-1b; SHV-1; OXA-1 & $q n r B 1$ & $+(\mathrm{cr})$ & NA; CIP; GM; K; TM; TET; SXT; TMP \\
\hline Kpp.350 & 23 July 2010 & Casablanca & $\mathrm{Kpl}$ & CTX-M-15; TEM-1b; SHV-1; OXA-1 & qnrS1 & $+(\mathrm{lb})$ & NA; CIP; GM; K; TM; TET; SXT; TMP \\
\hline Kpp.366 & 01 October 2010 & Casablanca & $\mathrm{Kpl}$ & $\begin{array}{l}\text { CTX-M-15; TEM-1b; SHV-12; OXA- } \\
1\end{array}$ & $\begin{array}{l}\text { qnrS1; } \\
\text { qnrA6 }\end{array}$ & $+(\mathrm{cr})$ & NA; CIP; GMㅎ K; TM; TET; SXT; TMP \\
\hline Kpp.343 & 17 July 2010 & Casablanca & $\mathrm{Kpl}$ & CTX-M-15; TEM-3; EBC-1464 & - & - & $N A ; C I P ; T E T^{b} ; I M P b$ \\
\hline Кpp.307 & 01 March 2010 & EL Jadida & $\mathrm{Kpl}$ & CTX-M-15; TEM-1; SHV-1; OXA-1 & - & $+(\mathrm{cr})$ & NA; CIP; GM; K; TM; TET; SXT; TMP; IMPD \\
\hline Kpp.386 & 26 October 2010 & Rabat & $\mathrm{Kpl}$ & CTX-M-15; TEM-1; SHV-11; OXA-1 & - & $+(\mathrm{cr})$ & NA; CIP; GM; K; TM; TET; SXT'; TMP \\
\hline Kpp.342 & 17 July 2010 & Casablanca & $\mathrm{Kpl}$ & CTX-M-15; TEM-1; SHV-11; OXA-1 & $q n r B 1$ & $+(\mathrm{cr})$ & NA; CIP; GM; K; TM; TET; SXT; TMP \\
\hline Kpp.332 & 08 June 2010 & EL Jadida & $\mathrm{Kpl}$ & CTX-M-15; TEM-1; SHV-11; OXA-1 & qnrS1 & $+(\mathrm{cr})$ & NA; CIP; GM; K; TM; TET; SXT; TMP \\
\hline Kpp.380 & 15 September 2010 & Casablanca & $\mathrm{Kpl}$ & CTX-M-15; TEM-1; SHV-28; OXA-1 & - & $+(\mathrm{cr})$ & NA; CIP; GM; K; TET \\
\hline Kpp.347 & 26 July 2010 & Casablanca & $\mathrm{Kpl}$ & SHV-12; ACT-2 & - & - & - \\
\hline
\end{tabular}

Abbreviations: AN, amikacin; CIP, ciprofloxacin; GM, gentamicin; IMP, imipenem; K, kanamycin; NA, nalidixic acid; SXT, Trimethoprim/sulfamethoxazole; TET, tetracycline; TM, tobramycin; TMP, trimethoprim; +, presence; -, negative.

aAll strains were resistant to the ampicillin, cefotaxime, ceftazidime and amoxicillin/clavulanic acid.

bIntermediate resistance level.

\section{Extended spectrum $\beta$-lactamase genes detected}

The CTX-M ESBL type was detected in 32 isolates $(94.1 \%)$, all belonged to CTX-M-1 group. Twenty-nine (85.3\%) belonged to the SHV family and twenty-nine $(85.2 \%)$ belonged to the TEM family. Twenty-three isolates $(67.6 \%)$ harbored $b l a_{\text {OXA-1 }}$ gene. Eight isolates produced more than one ESBL. The two bla genes encoding VEB and PER $\beta$-lactamases were not detected in any isolate (Table 3).

\section{Plasmid-mediated AmpC $\beta$-lactamse genes detected}

Among eight cefoxitin-resistant isolates, four harbored plasmidmediated AmpC $\beta$-lactamase (PABLs) genes as revealed by PCR multiplex; one isolates carried bla genes of the DHA group and three isolates carried genes belonging to the EBC group. Three types of PABLs were detected by PCR with specific primers and confirmed by sequencing analysis as DHA-1 (Kpp.338 isolate), ACT-2 (Kp.374 isolate) and a new PABLs named EBC-1464 (GenBank: FJ237368.1) (Kpp.318 and Kpp.343 isolates).

\section{Plasmid-mediated quinolone resistance genes}

Fourteen (41.1\%) ESBL-producing K. pneumoniae isolates were positive for $q n r$ genes; $q n r A-, q n r B$ - and $q n r S$-type alleles were detected in 1 (7.1\%), $8(57.1 \%)$ and $4(28.5 \%)$ K. pneumoniae isolates, respectively. These were found to be qnrA6, qnrB1, qnrB2 and $q n r S 1$ alleles by sequencing of PCR products (Table 3 ). Interestingly, two isolates carried simultaneously two types of $q n r$ genes: Kpp.303 harbored both $q n r B 1+q \eta r S 1$ and Kpp.366 carried both $q n r A 6+q n r S 1$.

Twenty-seven isolates (79.4\%) were positive for $a a c\left(6^{\prime}\right)-I b$ gene, of which 26 (96\% of all) isolates carried the $-\mathrm{cr}$ variant. The $a a c\left(6^{\prime}\right)-I b$ cr gene was detected in $85.7 \%$ (12/14 isolates) of $q n r$-positive isolates, 
Table 4 Transconjugants compared with their parental ESBL-producing $K$. pneumoniae

\begin{tabular}{|c|c|c|c|c|c|c|c|c|c|c|c|c|c|c|c|c|}
\hline \multirow[b]{2}{*}{ Code } & \multicolumn{12}{|c|}{$M I C\left(\mu g m I^{-1}\right)$} & \multicolumn{4}{|c|}{ Transfer } \\
\hline & $A M X$ & CTX & $C A Z$ & FEP & $A N$ & $K$ & $G M$ & Str & TET & $N A$ & $C I P$ & FOX & $\begin{array}{l}\text { Others } \\
\text { resistance }\end{array}$ & $\begin{array}{l}\text { Plasmid } \\
\text { (kb) }\end{array}$ & $\beta$-lactamases genes & $P M Q R$ genes \\
\hline Kpp.20 & $>256$ & $>256$ & 32 & 32 & 8 & 256 & 128 & $>256$ & $>256$ & 512 & 256 & 2 & TM,TMP & 125 & $\begin{array}{c}\text { CTX-M-15; TEM-1b; OXA- } \\
1\end{array}$ & $a a c\left(6^{\prime}\right)-I b-c r$ \\
\hline Tc20 & $>256$ & $>256$ & 32 & 16 & 2 & 64 & 64 & 64 & 128 & 0.50 & 0.12 & 0.50 & & & & \\
\hline Kpp.319 & $>256$ & $>256$ & 96 & $>256$ & 8 & 256 & 128 & $>256$ & 256 & 512 & 256 & 4 & TM, TMP, SXT & 125 & $\begin{array}{c}\text { CTX-M-15; TEM-1b; OXA- } \\
1\end{array}$ & $\begin{array}{c}q n r B 1 ; \operatorname{aac}\left(6^{\prime}\right)-l b- \\
c r\end{array}$ \\
\hline Tc319 & $>256$ & $>256$ & 48 & $>256$ & 4 & 128 & 8 & $>256$ & 128 & 32 & 4 & 0.50 & & & & \\
\hline Kpp.343 & $>256$ & $>256$ & $>256$ & $>256$ & 0.50 & 8 & 1 & 4 & 4 & 8 & 0.25 & $>256$ & - & 150 & EBC-1464 & - \\
\hline Tc343 & $>256$ & 256 & 256 & 0.12 & 0.12 & 2 & 0.50 & 2 & 2 & 0.50 & 0.02 & 128 & & & & \\
\hline $\mathrm{K}_{12} \mathrm{~J}_{5}$ & 4 & 0.50 & 0.50 & 0.12 & 0.12 & 0.75 & 0.50 & 2 & 1 & 0.50 & 0.02 & 0.50 & - & - & - & \\
\hline
\end{tabular}

Abbreviations: AMX, amoxicillin; AN, amikacin; CAZ, ceftazidime; CIP, ciprofloxacin; CTX, cefotaxime; FEP, cefepime; FOX, cefoxitin; GM, gentamicin; K, kanamycin; NA, calidixic acid; Str, streptomycin; SXT, trimethoprim/sulfamethoxazole; Tc, transconjugant; TET, tetracycline; TM, tobramycin; TMP, trimethoprim.

whereas only $51.8 \%$ (14/27 isolates) of qnr-negative isolates harbored this gene.

\section{Transfer of extended spectrum $\beta$-lactamase genes by conjugation experiment}

Transfer of $\beta$-lactamase genes was observed for three (Kpp20, Kpp319 and Kpp343) out of six isolates examined. Transfer frequencies ranged from $1.10^{6}$ to $2.10^{4}$ per donor cell. Susceptibility results of the clinical strains and their transconjugants are shown in Table 4. All transconjugants were resistant to amoxicillin, amoxicillin/clavulanic acid, cefotaxime and ceftazidime. Cefoxitin resistance was transferred in the Tc.343 transconjugant, whereas trimethoprim, tobramycin, gentamicin, kanamycin, streptomycin and tetracycline resistances were cotransferred in the Tc.20 and Tc.319 transconjugants (Table 4).

Kpp.343 isolate transferred successfully $b l a_{\mathrm{EBC}-1464}$ gene in E. coli $\mathrm{K}_{12} \mathrm{~J}_{5}$ recipient strain; this gene is carried by one conjugative plasmid of high molecular weight $(150 \mathrm{~kb})$. Analysis of gene of the isolates tested was also located on a plasmid of high molecular weight (125kb).

The plasmid pK319 of Tc.319 transconjugant strain additionally harbored the following four antibiotic resistance genes: $b l a_{\mathrm{OXA}-1}$, $b l a_{\text {TEM-1b, }} a a c\left(6^{\prime}\right)-I b-c r$ and $q n r B 1$ genes. The plasmid pK20 of Tc.20 transconjugant strain carried $b l a_{\mathrm{TEM}-1 \mathrm{~b}}, b l a_{\mathrm{OXA}-1}$ and $a a c\left(6^{\prime}\right)-I b-c r$.

\section{Exploration of the regions surrounding $\boldsymbol{b l a}_{\mathrm{CTX}-\mathrm{M}}$ genes}

PCR identified the insertion sequence ISEcpl upstream of the $b l a_{\mathrm{CTX}}$ $\mathrm{M}$ gene in 32 strains. The sizes of the PCR products were about $0.4 \mathrm{~kb}$ in all isolates except Kpp.443 strain. For this strain, the PCR fragment was about $1.1 \mathrm{~kb}$, suggesting the insertion of an additional DNA fragment. PCR with the IS26-specific primer produced no amplicon.

The genetic organization of the bla $a_{\mathrm{CTX}-\mathrm{M}-15}$ genes has been elucidated in the two host plasmids obtained by conjugation experiments (Tc20 and Tc319), in which bla $a_{\mathrm{CTX}-\mathrm{M}-15}$ gene transfer was successful. In addition, these transconjugants were characterized by their resistance genes diversity. In the mapping of the $3^{\prime}$ ends, only the PCR with primers P1A and orf477-IRR worked in all these cases, indicating that both modules terminated at the ISEcp1 IRR within orf 477 . The $b l a_{\mathrm{TEM}-1 \mathrm{~b}}$ gene was found to be located in a Tn3-like transposon. The tnpA gene of the Tn3 transposon is disrupted by ISEcp1-bla $a_{\mathrm{CTX}-\mathrm{M}-15}$. Long-PCR analysis confirmed that $b l a_{\mathrm{CTXM}-15}$ was located just upstream from $a a c\left(6^{\prime}\right)-I b-c r$. With the exception of $q n r B$ in pK.319, all the antibiotic resistance genes were clustered in a $12-\mathrm{kb}$ region.

\section{DISCUSSION}

The ESBL producing K. pneumoniae isolates are increasingly causing UTIs both in hospitalized and outpatients. ${ }^{1,15-16}$ The prevalence of ESBL producing isolates of $K$. pneumoniae varies in different countries. In European hospitals, it ranges from as low as $5 \%$ in Iceland and Estonia to as high as 59.3 to $100 \%$ in Ireland, Spain, Germany, Bulgaria and Romania. ${ }^{16-17}$ However, there is limited data regarding the prevalence of ESBLs producing $K$. pneumonia in community. In the present study, 34 of the $453 \quad(7.5 \%)$ K. pneumoniae isolates were ESBL producers. Higher rates of ESBL production among community-onset bacteremic UTIs caused by E. coli and K. pneumoniae have been reported from Taiwan (17.9\%) and Scotland $(12.5 \%) .3$

$\mathrm{KpI}$ is the most prevalent phylogenetic group in $\mathrm{K}$. pneumoniae isolates from Moroccan community as reported in previous studies. ${ }^{3,15}$ These preliminary results should be expanded by pulsed field gel electrophoresis or multilocus sequence typing methods to determine epidemiologic relationships among isolates.

ESBL-producing K. pneumoniae are commonly resistant to different antibiotic families, which contributes to the selection and persistence of MDR-ESBL strains and plasmids in community settings, resulting in the limitation of therapeutic options. ${ }^{18-20}$ In this study, the rate of MDR was alarmingly high (91.1\%), imipenem being the most active among the antibiotics tested. All these observations indicate the real threat of this problem, particularly when we know that the increasing use of carbapenems that have been widely used to treat serious infections with MDR K. pneumoniae, has led to the emergence of carbapenem-resistant isolates via acquired genes encoding carbapenem-hydrolyzing enzymes. ${ }^{20}$

ESBLs CTX-M types have been known for their rapid spread in African and European communities. ${ }^{3,9,21-22}$ The first detection of bla $a_{\mathrm{CTX}-\mathrm{M}}$ (CTX-M-15 and CTX-M-28) in Morocco was documented in 2010 at the teaching hospital Ibn Rochd in Casablanca. ${ }^{6}$ In a previous study, we have investigated, for the first time, the dissemination of these enzymes among community ESBL producing Enterobacteriaceae isolates responsible for UTIs, including a restricted sample of $K$. pneumoniae strains. ${ }^{9}$ To contribute to a better understanding of the epidemiology of 
these enzymes at local and national level, other cities are included in the present work and therefore, the sample was larger. It was remarkable that, $91.1 \%$ of our ESBL-producing K. pneumoniae isolates carried $b l a_{\mathrm{CTX}-\mathrm{M}-15}$; this proves that $b l a_{\mathrm{CTX}-\mathrm{M}-15}$ gene is highly endemic in Moroccan community. Seventy-four percent of strains harboring the $b l a_{\text {CTX-M-15 }}$ gene also possessed a $b l a_{\text {OXA-1 }}$ gene (Table 3 ), presumably explaining the high percentage of non-susceptibility to amoxicillin-clavulanic acid. This genes combination has been found in the same strain in Portugal. ${ }^{21}$ The $b l a_{\mathrm{CTX}-\mathrm{M}-15}$ plus $b l a_{\mathrm{OXA}-1}$ plus $b l a_{\mathrm{TEM}-1}$ or $b l a_{\mathrm{TEM}-1 \mathrm{~b}}$ was coexpressed by 23 strains. This genes association has been also reported in strains from Portugal. ${ }^{21}$ However, the combination of $b l a_{\text {CTX-M-15 }}$ plus $b l a_{\text {TEM-3 }}$ reported here is, to our knowledge, first in Africa. Twenty-nine ESBL-producing $K$. pneumoniae isolates carried $b l a_{\mathrm{SHV}}$, of which, twenty-three encoded non-ESBL types. It is noteworthy that this study reported the detection of SHV-28, SHV-36 and -110-producing isolates for the first time in Morocco.

Plasmid analysis revealed that the transconjugants (Tc.20 and Tc.319) harbored large plasmids of about $125 \mathrm{~kb}$ and these plasmids (pK.319 and pK.20) carry only two known resistance genes, $b l a_{\text {TEM-1b }}$ and $b l a_{\text {CTX-M-15. These findings suggest that the CTX-M-15 allele is }}$ carried on large conjugative plasmids that are well adapted and constantly exchanged by lateral gene transfer among the $K$. pneumoniae isolates. Previous studies have shown that $b l a_{\mathrm{TEM}}$ genes are carried by three of the earliest described bacterial transposons, namely Tn1, Tn2 and $\operatorname{Tn} 3$. These transposons contain the transposase and resolvase genes, $\operatorname{tnp} A$ and $\operatorname{tn} p R$, as well as a resolution site. ${ }^{23}$ The $b l a_{\mathrm{TEM}-1}$ gene was found to be located in a Tn3-like. Interestingly, the tnpA gene of the Tn 3 transposon is disrupted by ISEcp1-bla $a_{\mathrm{CTX}-\mathrm{M}-15}$ due to ISEcp1mediated transposition. The mechanism involves the left inverted repeat of ISEcP1 and a right inverted repeat (IRR1), which resembles the IRR of ISEcp1. ${ }^{24}$

The resistance of $K$. pneumoniae to cephamycins have also arisen by acquisition of plasmids containing the chromosomally derived AmpC $\beta$-lactamase. ${ }^{6}$ In Morocco, the PABLs types previously detected were DHA-1 and CMY-2., ${ }^{6,25}$ In this study, we detected eight cefoxitinresistant K. pneumoniae, of which four isolates harbored PABLs genes. They could become an important cause, in addition to ESBLproducing isolates, of increasing resistance to extended spectrum $\beta$-lactams in Moroccan community. The major finding of this study was the report of the occurrence of the ACT- $2 \beta$-lactamase for the first time in Morocco. Furthermore, we detected two strains that harbored $b l a_{\mathrm{EBC}-1464}$ gene. To the best of our knowledge, this is the second report of EBC-1464 $\beta$-lactamase in the world. The EBC-1464 $\beta$-lactamase was a novel PABL detected in a $K$. pneumoniae isolate from China (GenBank: FJ237368.1). Cefoxitin resistance in AmpC non-producers could be due to some other resistance mechanism, such as lack of permeation of porins. ${ }^{26}$

In conclusion, our results demonstrate that the resistance of ESBLproducing $K$. pneumoniae responsible for UTIs to a wide variety of common antimicrobials continue to become a serious global health concern that could complicate treatment strategies. We also report the first detection in Morocco of $b l a_{\mathrm{EBC}-1464}$ and the diversity of the $\beta$-lactamase genes of community $K$. pneumoniae isolates, with the CTX-M-15 being most common. To ensure appropriate therapy, current knowledge of antibiotic susceptibility of the organisms that cause UTIs is mandatory. ${ }^{1}$ In this context, routine screening for ESBLs producers in the laboratory is of great importance for their early identification and management.
1 Tankhiwale, S. S., Jalgaonkar, S. V., Ahamad, S. \& Hassani, U. Evaluation of extended spectrum beta lactamase in urinary isolates. Indian J. Med. Res. 120, 553-556 (2004).

2 Khurana, S., Taneja, N. \& Sharma, M. Extended spectrum beta lactamases mediated resistance in urinary tract isolates of family Enterobacteriaceae. Indian J. Med. Res. 116, 145-149 (2002)

3 Younes, A., Hamouda, A., Dave, J. \& Amyes, S. G. Prevalence of transferable blaCTXM-15 from hospital- and community-acquired Klebsiella pneumoniae isolates in Scotland. J. Antimicrob. Chemother. 66, 313-318 (2011).

4 Baudry, P. J. et al. Mechanisms of resistance and mobility among multidrug-resistant CTX-M-producing Escherichia coli from Canadian intensive care units: the 1st report of QepA in North America. Diagn. Microbiol. Infect. Dis. 63, 319-326 (2009).

5 Yang, Y. S. et al. Community-onset bacteremic urinary tract infections caused by extended-spectrum beta-lactamase-producing Escherichia coli and Klebsiella pneumoniae. J. Med. Sci. 29, 265-268 (2009).

6 Bouchakour, M. et al. Plasmid-mediated quinolone resistance in expanded spectrum beta lactamase producing Enterobacteriaceae in Morocco. J. Infect. Dev. Ctries 4 799-803 (2010)

7 Lahlou, A., Chegri, M. \& L'kassmi, H. Epidemiology and antibiotic resistance of Enterobacteriaceae isolated in urinary tract infections at the Moulay Ismail Military Hospital of Meknes. Antib. 11, 90-96 (2009).

8 Benouda, A., Touzani, O., Khairallah, M. T., Araj, G. F. \& Matar, G. M. First detection of oxacillinase-mediated resistance to carbapenems in Klebsiella pneumoniae from Morocco. Ann. Trop. Med. Parasitol. 104, 327-330 (2010).

9 Barguigua, A. et al. Characterization of ESBL-producing Escherichia coli and Klebsiella pneumoniae isolates from community in Morocco. J. Med. Microbiol. 60, 1344-1352 (2011).

10 Pérez-Pérez, F. J. \& Hanson, N. D. Detection of plasmid-mediated AmpC $\beta$-lactamase genes in clinical isolates by using multiplex PCR. J. Clin. Microbiol. 40, 2153-2162 (2002).

11 Macrina, F. L., Kopecko, D. J., Jones, K. R., Ayers, D. J. \& McCowen, S. M. A multiple plasmid-containing Escherichia colistrain: convenient source of size reference plasmid molecules. Plasmid 1, 417-420 (1978).

12 Eckert, C. et al. Dissemination of CTX-M-type $\beta$-lactamases among clinical isolates of Enterobacteriaceae in Paris, France. Antimicrob. Agents Chemother. 48, 1249-1255 (2004).

13 Literacka, E. et al. blaCTX-M genes in Escherichia coli strains from Croatian hospitals are located in new (blaCTX-M-3a) and widely spread (blaCTX-M-3a and blaCTX-M-15) genetic structures. Antimicrob. Agents Chemother. 53, 1630-1635 (2009).

14 Lavollay, M. et al. Clonal dissemination of a CTX-M-15 $\beta$-lactamase-producing Escherichia coli strain in the Paris area, Tunis, and Bangui. Antimicrob. Agents Chemother. 50, 2433-2438 (2006).

15 Valverde, A., Coque, T. M., García-San Miguel, L., Baquero, F. \& Cantón, R. J. Complex molecular epidemiology of extended-spectrum beta-lactamases in Klebsiella pneumoniae: a long-term perspective from a single institution in Madrid. Antimicrob. Chemother. 61, 64-72 (2008).

16 Coque, T. M., Baquero, F. \& Canton, R. Increasing prevalence of ESBL producing Enterobacteriaceae in Europe. Euro. Surveill. 13 (2008).

17 European Centre for Disease Prevention and Control (ECDC). Antimicrobial resistance surveillance in Europe 2010. Annual Report of the European Antimicrobial Resistance Surveillance Network (EARS-Net): Stockholm: ECDC; 2010. http://www.ecdc.europa.eu/en/publications/Publications/1111_SUR_AMR_data.pdf.pdf. 2011, accessed 22 August 2012.

18 Winokur, P. L., Canton, R., Casellas, J. M. \& Legakis, N. Variations in the prevalence of strains expressing an extended spectrum beta lactamase phenotype and characterization of isolates from Europe, the Americas and the Western Pacific region. Clin. Infect. Dis. 32, S94-S103 (2001).

19 Paterson, D. L. et al. Epidemiology of ciprofloxacin resistance and its relationship to extended-spectrum $\beta$-lactamase production in Klebsiella pneumoniae isolates causing bacteremia. Clin. Infect. Dis. 30, 473-478 (2000).

20 Queenan, A. M. \& Bush, K. Carbapenemases: the versatile beta-lactamases. Clin. Microbiol. Rev. 20, 440-458 (2007).

21 Mendonça, N., Leitão, J., Manageiro, V., Ferreira, E. \& Caniça, M. Spread of extended spectrum beta-lactamase CTX-M-producing Escherichia coli clinical isolates in community and nosocomial environments in Portugal. Antimicrob. Agents Chemother. 51, 1946-1955 (2007)

22 Rodríguez-Baño, J., López-Cerero, L., Navarro, M. D., Díaz de Alba, P. \& Pascual, A Faecal carriage of extended-spectrum beta-lactamase-producing Escherichia coli: prevalence, risk factors and molecular epidemiology. J. Antimicrob. Chemother. 62 1142-1149 (2008).

23 Mshana, S. E. et al. Conjugative IncFI plasmids carrying CTX-M-15 among Escherichia coli ESBL producing isolates at a university hospital in Germany. BMC Infect. Dis. 9 , 97 (2009)

24 Smet, A. et al. Complete nucleotide sequence of CTX-M-15-plasmids from clinical Escherichia coli isolates: insertional events of transposons and insertion sequences. PLoS One 5, e11202 (2010).

25 Bouchrif, B. et al. Ceftazidime-resistant Salmonella enterica, Morocco. Emerg. Infect. Dis. 15, 1693-1695 (2009).

26 Hernández-Allés, S. et al. Development of resistance during antimicrobial therapy caused by insertion sequence interruption of Porin genes. Antimicrob. Agents Chemother. 43, 937-939 (1999). 